\title{
When a maternal heterozygous mutation of the CYP24A1 gene leads to infantile hypercalcemia through a maternal uniparental disomy of chromosome 20
}

\author{
Marguerite Hureaux ${ }^{1,2,3^{*}} \oplus$, Sandra Chantot-Bastaraud ${ }^{4}$, Kévin Cassinari $^{5}$, Edouard Martinez Casado ${ }^{6}$, \\ Ariane Cuny ${ }^{6}$, Thierry Frébourg ${ }^{5}$, Rosa Vargas-Poussou ${ }^{1,2}$ and Anne-Claire Bréhin ${ }^{5}$
}

\begin{abstract}
Background: Infantile hypercalcemia is an autosomal recessive disorder caused either by mutations in the CYP24A1 gene (20q13.2) or in the SLC34A1 gene (5q35.3). This disease is characterized by hypercalcemia, hypercalciuria and nephrocalcinosis in paediatric patients.

Maternal uniparental disomy of chromosome 20 [UPD(20)mat], resulting in aberrant expression of imprinted transcripts at the GNAS locus, is a poorly characterized condition. UPD(20)mat patients manifest a phenotype similar to that of Silver-Russell syndrome and small for gestational age-short stature.

Case presentation: We report here the genetic and clinical characterization of a male child with a phenotype of infantile hypercalcemia, postnatal growth retardation, and minor dysmorphic features. Genetic analysis using a next generation sequencing panel revealed a homozygous pathogenic variant of CYP24A1. The absence of the variant in the father led to microsatellite segregation analysis, suggestive of UPD. SNP-array revealed a large terminal copy neutral loss of heterozygosity leading to CYP24A1 homozygosity. SNP-array data of parent-child trio confirmed a UPD(20) mat responsible for both infantile hypercalcemia and Silver-Russell syndrome-like traits.
\end{abstract}

Conclusion: This is the first report of uniparental disomy of chromosome 20 revealed by infantile hypercalcemia related to CYP24A1 biallelic homozygous variants, underlying the importance of controlling allelic segregation in cases of homozygosity.

Keyword: Uniparental disomy of chromosome 20, Infantile hypercalcemia, CYP24A1, Silver-Russell-like syndrome

\section{Background}

Infantile hypercalcemia $(\mathrm{IH})$ is a rare genetic cause of nephrocalcinosis typically occurring in paediatric subjects and characterized by inappropriate increment of calcitriol with persistent hypercalcemia, absorptive

*Correspondence: marguerite.hureaux@aphp.fr

${ }^{1}$ Département de Génétique, Assistance Publique Hôpitaux de Paris, Hôpital Européen Georges Pompidou, 20 rue Leblanc, 75015 Paris, France

Full list of author information is available at the end of the article hypercalciuria, suppressed parathyroid hormone level and nephrocalcinosis [1]. Some patients remain asymptomatic during infancy and present later in life with recurrent episodes of nephrolithiasis [2].

This condition results from biallelic loss-of-function variations in the CYP24A1 gene, involved in vitamin D catabolism and in calcium homeostasis (IH type 1; OMIM 143880, 20q13.2) [3], or in the SLC34A1 gene, encoding for the renal sodium-phosphate transporter NaPi-IIa (IH type 2; OMIM 616963, 5q25.3) [4]. original author(s) and the source, provide a link to the Creative Commons licence, and indicate if changes were made. The images or other third party material in this article are included in the article's Creative Commons licence, unless indicated otherwise in a credit line to the material. If material is not included in the article's Creative Commons licence and your intended use is not permitted by statutory regulation or exceeds the permitted use, you will need to obtain permission directly from the copyright holder. To view a copy of this licence, visit http://creativecommons.org/licenses/by/4.0/. The Creative Commons Public Domain Dedication waiver (http://creativeco mmons.org/publicdomain/zero/1.0/) applies to the data made available in this article, unless otherwise stated in a credit line to the data. 
Uniparental disomy (UPD) is the inheritance of both homologous chromosomes of a specific chromosome pair from a single parent with two main subtypes: heterodisomy if the two different homologues chromosomes are transmitted and isodisomy if identical homologues chromosomes are transmitted [5]. UPD has been described for almost all the human chromosomes, and could lead to an abnormal phenotype, particularly if it involves an imprinted region [5]. UPD of chromosome 20 is a rare condition associated with a variable phenotype depending on its parental origin. Paternal uniparental disomy of chromosome 20, that includes the GNAS locus, has been identified in about 20 sporadic patients with pseudohypoparathyroidism 1B [6] whereas UPD(20)mat with normal karyotype (Mulchandani-Bhoj-Conlin syndrome, OMIM \#617352) has been identified in 20 patients with pre- and post-natal growth failure, severe short stature with proportional head circumference and profound feeding difficulty phenotype [7-10]. Those clinical features overlap with that of Silver-Russell syndrome (SRS) and small for gestational age-short stature (SGA-SS) for which genetic bases are heterogeneous; the most frequent being imprinting anomalies of chromosomes 7 and $11[11,12]$.

In this report, we present the first patient with $\operatorname{UPD}(20)$ mat revealed by phenotype of IH related to CYP24A1. This exceptional situation in rare metabolic disease with recessive transmission underlines the importance of allelic segregation control in cases of homozygosity to determine the risk of recurrence in siblings.

\section{Case presentation}

The patient, a 3 years old boy (Fig. 1), is the third child of healthy unrelated French parents. The mother, 45 years old at the time of conception, had two healthy children from a previous union.

The patient was born at a gestational age of 37 weeks with a birth weight of $2750 \mathrm{~g}$ (32nd percentile), a birth length of $46 \mathrm{~cm}$ (13th percentile) and a birth head circumference of $34 \mathrm{~cm}$ (55th percentile). As usually, he had vitamin D prescription (1200 UI of cholecalciferol/ day) that he received irregularly during the first 2 months of life. At the age of 9 months, he was referred to the Department of Paediatrics due to growth retardation. Biological tests and clinical examination were normal.

At the age of 12 months, he was evaluated for persistent short stature and developmental delay with feeding difficulties and vomiting. A parental abuse was suspected but feeding difficulties and vomiting persisted during hospitalisation. His weight was $6270 \mathrm{~g}(-2.5 \mathrm{SD})$ and his length was $70.5 \mathrm{~cm}(-2.5 \mathrm{SD})$. On evaluation, there was no evidence for a secondary growth disorder. Except a mild developmental delay, neurological examination was

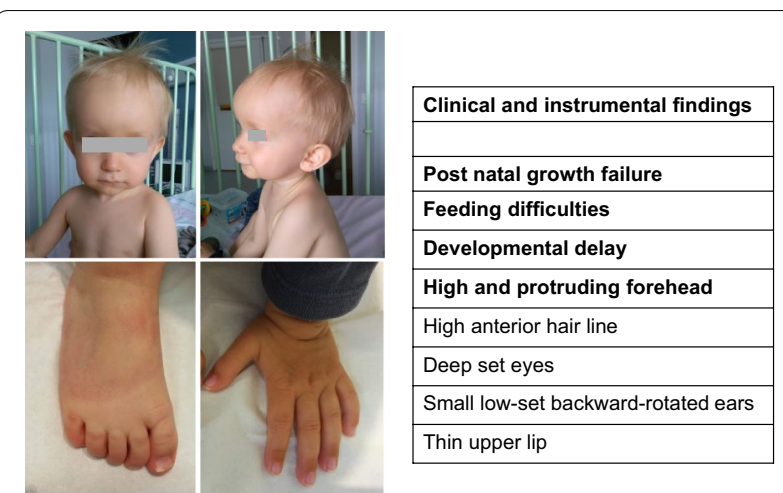

Fig. 1 Clinical characterization of the case. Frontal and lateral view of the proband at the age of 14 months. Note the frontal bossing, high anterior hair line, deep set eyes, small low-set backward-rotated ears, and thin upper lip. Other clinical findings are listed in the side table, where 3 out of $6 \mathrm{NH}$-CSS for SRS are in bold characters

normal. Cardiac ultrasonography and cerebral MRI did not reveal any abnormality. Thyroid function tests and concentrations of IGF-1, calcium, inorganic phosphate and alkaline phosphatase were all within normal limits. There was no evidence of a metabolic disease (Table 1).

Clinical examination suggested a mild facial dysmorphism with a frontal bossing, a high anterior hairline, deep-set eyes, small low-set backward-rotated ears, and a thin upper lip corresponding at 3 out 6 on the Netchine-Harbison clinical scoring system for SRS criteria [11] (Fig. 1). The clinical features of our patient are compared to a cohort of UPD(20)mat reviewed by Hjortshøj et al. [13] (Supplementary Table 1).

After this evaluation, calcium/vitamin D supplementation was resumed.

At the age of 18 months, a renal ultrasonography showed a bilateral nephrocalcinosis grade II, associated to hypercalciuria, hypophosphatemia, increased $1,25 \mathrm{OH}$ vitamin $\mathrm{D}$ with abnormally low parathyroid hormone level (PTH) (Table 1).

\section{Methods of relevant genetic analysis Molecular analysis of CYP24A1}

Genomic DNA was isolated from white blood cells using standard procedures. Next generation sequencing (NGS) was performed using a specifically designed panel for known genes involved in tubulopathies or nephrocalcinosis as previously described $[14,15]$, and analysed on a Miseq Plateform (Illumina, San Diego, CA). All of the targeted regions were covered at $>30 \mathrm{X}$. Bioinformatics analysis was performed using an in-house pipeline (Polyweb software interface designed by the Paris University Bioinformatics platform) targeting on the region of interest of $\mathrm{IH}$ (CYP24A1 and SLC34A1 genes). For 
Table 1 Biological characteristics

\begin{tabular}{|c|c|c|c|c|}
\hline & 12 months & 14 months & 18 months & 40 months \\
\hline \multicolumn{5}{|l|}{ Plasma [normes at age] } \\
\hline Creatinine $(\mu \mathrm{mol} / \mathrm{l})$ [15-37] & 34 & 25 & 21 & 31 \\
\hline CO2 total (mmol/l) [19-24] & 17 & 15 & 17 & 24 \\
\hline Potassium (mmol/l) [3.1-4.7] & 4.8 & 4.7 & 4.2 & 4 \\
\hline Sodium (mmol/l) [133-140] & 137 & 139 & 134 & 141 \\
\hline Magnesium (mmol/l) [0.6-1.3] & & & 0.79 & \\
\hline Chloride (mmol/l) [95-105] & 100 & 100 & 96 & 105 \\
\hline Total calcium (mmol/l) [2.20-2.83] & 2.54 & 2.73 & 2.52 & 2.54 \\
\hline \multicolumn{5}{|l|}{ Ion calcium (mmol/l) [1.22-1.40] } \\
\hline Phosphate (mmol/l) [1.55-2.39] & 1.27 & 1.4 & 1.15 & 1.52 \\
\hline PTH (ng/L) [7-31] & & $<4$ & 7 & 8 \\
\hline 25 OH-vitamin D (ng/ml) [50-80] & & 62 & 72 & 63 \\
\hline $1,25(\mathrm{OH})_{2}$-vitamin D (pg/l) [30-150] & & & 200 & 165 \\
\hline \multicolumn{5}{|l|}{ Urine } \\
\hline Calcium/creatinin (mmol/l//mmol/l) $[<1.1]$ & & & 1.16 & \\
\hline Sodium (mmol/l) & & & 37 & \\
\hline Phosphate (mmol/l) & & & 11.4 & \\
\hline TRPh (\%) & & & 88 & \\
\hline
\end{tabular}

Abnormal values evocative of $\mathrm{IH}$ phenotype in bold

in silico analysis Alamut V.2.10 software (Interactive Biosoftware, Rouen, France; http://www.interactivebios oftware.com) was used. All variants identified were confirmed by Sanger sequencing, on a 3730xl DNA Analyzer (Applied Biosystems, ThermoFischer Scientific Waltham, Massachusetts, USA). Variants of interest were classified according the American College of Molecular Genetics guidelines [16].

\section{Microsatellite analysis}

Using Total DNA previously extracted, we performed polymerase chain reaction (PCR) to amplify 5 microsatellite loci located on chromosome 20. (Details of microsatellites used and of amplification protocol in Supplementary data Table 2 and supplementary Methods 1). Microsatellite genotypes were determined by Gene Mapper Software v5.0 (ThermoFischer). PCR was performed several times to confirm genotypes reproducibility.

\section{SNP-array}

Patient and parents were genotyped using HumanOmniExpress-24 microarrays (Illumina, San Diego, CA, USA) which contain up to 710,000 markers. Automated Illumina microarray experiments were performed according to the manufacturer's instructions. Images were acquired using an iScan System (Illumina). Image analysis and automated Copy Number Variant (CNV) calling were performed using GenomeStudio v.2.0 and CNVPartition v.3.1.6. The Single Nucleotid Polymorphisms
(SNP) profiles were analyzed by examination of signal intensity (Log $\mathrm{R}$ ratio, i.e. In (sample copy number/reference copy number)) and allelic composition (BAF, i.e. B Allele Frequency). The Log $\mathrm{R}$ ratio can detect $\mathrm{CNV}$ and the BAF can estimate the genotype of each SNP: e.g. for an SNP with 2 copies, $\mathrm{BAF}=0$ means an (AA) genotype, $\mathrm{BAF}=0.5$ means an $(\mathrm{AB})$ genotype, $\mathrm{BAF}=1$ means a (BB) genotype.

Results were indicated according to the International System for Human Cytogenomic Nomenclature (ISCN 2016).

\section{Results}

First-line genetic explorations, systematic fragile $\mathrm{X}$ syndrome at FRAXA locus and array-CGH (Array comparative genomic hybridization; Agilent $180 \mathrm{~K}$ ), were normal. Methylation test for the two differentially methylated regions (DMRs) ICR1 and ICR2 regions at chromosome 11p15, the GRB10-PEG1/MEST loci at chromosome 7 and the DLK1-MEG3 locus at chromosome 14q32 were negative excluding main causes of Silver-Russell syndrome.

NGS analysis identified a homozygous variant in exon 9 of the CYP24A1 gene: c.[1226 T $>C]$; $[(1226 \mathrm{~T}>\mathrm{C})]$, p.[(Leu409Ser);(Leu409Ser)]. This variant, previously reported [4], was classified as pathogenic variant (class 5) using the following criteria PS3 PS4, PM2, PP3, PP5 of the ACMG guidelines, described in supplementary Methods [16]. The tool used to evaluate Copy Number 
Variant integrated to the NGS analysis software showed normal CNV ratios among the whole gene. Parental DNA study showed that the variant was inherited from the mother, who was heterozygous carrier, and that the father was not harbouring the variant. First hypothesis was non-paternity, excluded by analysis of 7 unlinked microsatellite markers located on 6 chromosomes (supplementary Table 2). Further microsatellite analysis targeted on chromosome 20 in 5 loci spread on the two arms 20p and 20q showed that (1) index case was homozygote for AAT269, GO8049, and UT254 located on 20q, (2) haplotype AAT269 (242 bp), GO8049(296 pb), pathogenic variation c.1226 T>C. and UT254 (300 bp) is inherited from the mother, and that (3) D20S103 and D20S853 located on $20 \mathrm{p}$, are present in both father, mother and patient at heterozygous state, that could correspond to different paternal or maternal recombination mechanisms during meiosis. In conclusion, microsatellites segregation showed homozygosity for long arm's markers AAT269, GO8049, and UT254 markers; and NGS and Sanger sequencing confirmed the homozygous status of the pathogenic variant in $C Y P 24 A 1$. Furthermore, lack of paternal contribution for 3 of them suggested uniparental maternal disomy (Fig. 2a).

SNP-array was performed on patient's DNA in order to test this hypothesis and showed a large terminal homozygous region of $13.6 \mathrm{Mb}$ size without copy loss from 20q13.13 to 20qter including the CYP24A1 locus (Fig. 2b). This homozygous state only concerned chromosome 20, and therefore was not evocative of consanguinity, according to the ACMG guidelines of 2013 [17] Subsequently, child and parental genotypes determined by SNP-array probes were compared to each other and demonstrated maternal inheritance for the whole 20 chromosome involving combination of heterodisomic and isodisomic region. Such pattern of heterodisomic

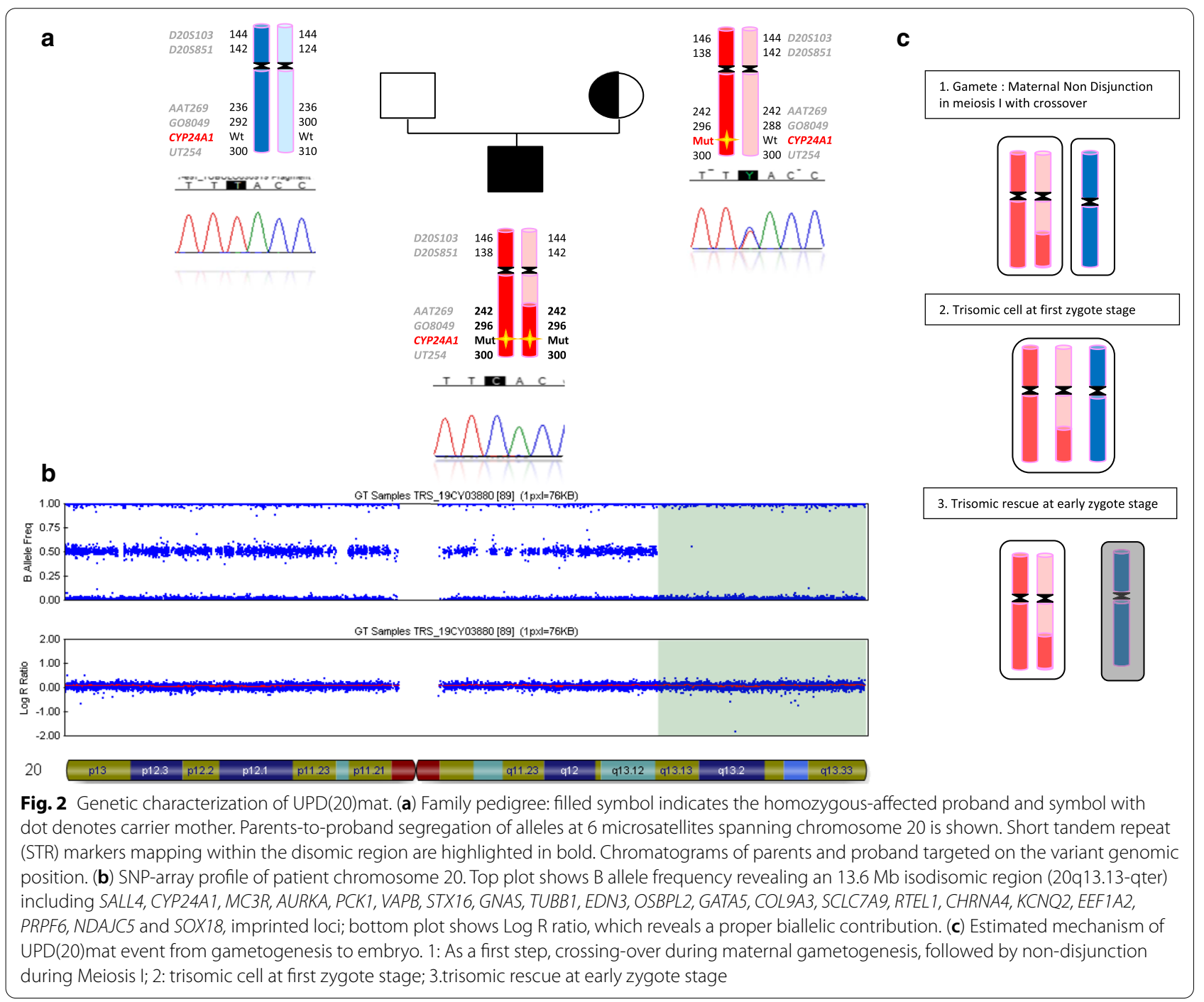


region including pericentromeric region and isodisomic region is consistent with uniparental disomy subsequent to nondisjunction during meiosis I after meiotic crossover and postzygotic trisomy rescue (Fig. 2b). Child and both parents had normal karyotypes ruling out chromosomal rearrangement prone to 3:1 disjunction with subsequent trisomy rescue (reciprocal translocation between imprinted 20 chromosome and other).

\section{Discussion}

We report here the case of a young boy with $\operatorname{UPD}(20)$ mat leading to infantile hypercalcemia. At the first examination, the 12 months boy had post-natal growth retardation with feeding difficulties and vomiting, and facial dysmorphism associated to major growth retardation led to explore main causes of Silver-Russell syndrome. However, methylation analysis of chromosomes 7, and 11 were normal, corresponding to approximately 40 to $60 \%$ of known causes of this syndrome [18]. Later, the fortuitous discovery of nephrocalcinosis and hypercalciuria led to suspect an infantile hypercalcemia. NGS sequencing confirmed this diagnosis with the identification of a homozygous pathogenic missense nucleotide variation in the CYP24A1 gene. Parental segregation revealed that the mutation was present in heterozygous state only in the patient's mother and microsatellites segregation suggested maternal uniparental disomy with isodisomic region neighboring CYP24A1 locus. This data and the persistence of feeding difficulties and growth retardation despite of cessation of vomiting led to UPD(20)mat suspicion. Trio SNP-array analysis and child's pattern of heterodisomic and isodisomic region confirmed the diagnosis of maternal disomy of chromosome 20 with isodisomic region generated by meiotic crossover during maternal gametogenesis. As pericentromeric markers showed heterodisomy, a maternal meiosis I error was probably the first step of this UPD formation. As the mother was 45 years old at the time of conception, this observation corroborates the major role of maternal agein non-disjunction mechanism in meiosis I [19].

Patients with $\operatorname{UPD}(20)$ mat mostly present with postnatal growth retardation, small for gestational age, feeding difficulties or low body mass index. In half of cases, developmental delay and hypotonia and slight clinical dysmorphic features can be found [http://cs-tl. de/DB/CA/UPD/0-Start.html [accessed 03/15/2021]]. Only two cases with hetero-isodisomy also present hypercalcemia associated with low $\mathrm{PTH}$, suggestive of IH phenotype; without confirmation of the involvement of the CYP24A1 gene [7]. In other cases described of $\mathrm{UPD}(20)$ mat, no other clinical findings evocative of $\mathrm{IH}$ were reported. Beside, IH patients present with hypercalcemia, low PTH, normal to high 1-25 OH vitamin
D. Clinically, IH patients present low body mass index or failure to thrive, polyuria or dehydration, hypotonia and nephrocalcinosis at ultrasound analysis [3]. No neurodevelopmental delay has been reported associated to IH.

Symptoms such as growth retardation or feeding difficulties are nonspecific and can have a variety of causes. In our case, the $\mathrm{IH}$ phenotype associating hypercalcemia and nephrocalcinosis initially led to the diagnosis of IH and secondarily of UPD(20)mat, in front of a set of arguments such as absence of mutation in the father, persistence of growth retardation and advanced maternal age. Moreover, the patients did not present any other clinical or biochemical anomaly suggestive of other recessive disorder, neither a weak trisomy 20 mosaicism.

In conclusion, this report shows that $\operatorname{UPD}(20)$ mat explains the child's phenotype since growth retardation and psychomotor retardation overlaps with SRS features and correspond to elements classically described in Mulchani-Bhoj-Conlin syndrome. To our knowledge, this is the first reported case of $\operatorname{UPD}(20)$ mat revealing a deficiency in CYP24A1. This exceptional situation in rare diseases of the metabolism with recessive transmission underlines the importance of controlling allelic segregation in cases of homozygosity in order to precisely determine the risk of recurrence in sibling.

\section{Supplementary Information}

The online version contains supplementary material available at https://doi. org/10.1186/s13039-021-00543-4.

Additional file 1.

\section{Acknowledgements}

The authors thank the patient and her family, as well as all the medical and technical staff for their cooperation, which made this work possible.

\section{Authors' contributions}

M. Hureaux, K. Kassinari, S.Chantot-Bastaraud, R. Vargas-Poussou and AC. Brehin contributed equally to design, analyze of data, redaction and final approval of the manuscript.

E. Martinez Casado, A. Cuny, and T Frébourg contributed to final approval of the manuscript.

Funding

The authors didn't receive any specific funding for this work.

Availability of data and materials

The authors confirm that the data supporting the findings of this study are available within the article and its supplementary materials.

\section{Declarations}

Ethics approval and consent to participate

The authors confirm that the study conforms to recognized standards of European Medicines Agency Guidelines for Good Clinical Practice and has been performed in accordance with local ethical approvals. 


\section{Consent for publication}

Written consent for publication of images and clinical information was obtained from both parents.

\section{Competing interests}

The authors declare no conflict of interest.

\section{Author details}

${ }^{1}$ Département de Génétique, Assistance Publique Hôpitaux de Paris, Hôpital Européen Georges Pompidou, 20 rue Leblanc, 75015 Paris, France. ${ }^{2}$ Reference Centre for Hereditary Renal Diseases (MARHEA), Paris, France.

${ }^{3}$ Paris Cardiovascular Research Center, INSERM, Paris, France. ${ }^{4}$ Assistance Publique-Hôpitaux de Paris, Departement de Genetique Medicale, Hôpital Trousseau, 75012 Paris, France. ${ }^{5}$ Normandie Univ, UNIROUEN, Inserm U1245 and Rouen University Hospital, Department of Genetics and Reference Center for Developmental Disorders, Normandy Center for Genomic and Personalized Medicine, 76000 Rouen, France. ${ }^{6}$ Department of Pediatrics, Centre Hospitalier Universitaire de Rouen, 76000 Rouen, France.

Received: 15 February 2021 Accepted: 4 April 2021

Published online: 05 May 2021

\section{References}

1. De Paolis E, Scaglione GL, De Bonis M, Minucci A, Capoluongo E. CYP24A1 and SLC34A1 genetic defects associated with idiopathic infantile hypercalcemia: from genotype to phenotype. Clin Chem Lab Med. 2019;57(11):1650-67. https://doi.org/10.1515/cclm-2018-1208.

2. Jones G, Kottler ML, Schlingmann KP. Genetic diseases of vitamin D metabolizing enzymes. Endocrinol Metab Clin North Am. 2017:46(4):1095-117. https://doi.org/10.1016/j.ecl.2017.07.011.

3. Schlingmann KP, Kaufmann M, Weber S, et al. Mutations in CYP24A1 and idiopathic infantile hypercalcemia. N Engl J Med. 2011;365(5):410-21. https://doi.org/10.1056/NEJMoa1103864.

4. Schlingmann KP, Ruminska J, Kaufmann M, et al. Autosomal-recessive mutations in SLC34A1 encoding sodium-phosphate cotransporter 2A cause idiopathic infantile hypercalcemia. J Am Soc Nephrol. 2016:27(2):604-14. https://doi.org/10.1681/ASN.2014101025.

5. Benn P. Uniparental disomy: Origin, frequency, and clinical significance [published online ahead of print, 2020 Nov 11]. Prenat Diagn. 2020;https://doi.org/10.1002/pd.5837. https://doi.org/10.1002/pd.5837

6. Colson C, Decamp M, Gruchy N, et al. High frequency of paternal iso or heterodisomy at chromosome 20 associated with sporadic pseudohypoparathyroidism 1B. Bone. 2019;123:145-52. https://doi.org/10.1016/j. bone.2019.03.023.

7. Kawashima S, Nakamura A, Inoue T, et al. Maternal uniparental disomy for chromosome 20: physical and endocrinological characteristics of five patients. J Clin Endocrinol Metab. 2018;103(6):2083-8. https://doi.org/10. 1210/jc.2017-02780.

8. Mulchandani S, Bhoj EJ, Luo M, et al. Maternal uniparental disomy of chromosome 20: a novel imprinting disorder of growth failure. Genet Med. 2016;18(4):309-15. https://doi.org/10.1038/gim.2015.103.

9. Eggermann T, Mergenthaler S, Eggermann K, Albers A, Linnemann K, Fusch C, Ranke MB, Wollmann HA. Identification of interstitial maternal uniparental disomy (UPD) (14) and complete maternal UPD(20) in a cohort of growth retarded patients. J Med Genet. 2001;38(2):86-9. https://doi.org/10.1136/jmg.38.2.86.PMID:11158171;PMCID:PMC1734807.

10. Joshi RS, Garg P, Zaitlen N, Lappalainen T, Watson CT, Azam N, Ho D, Li X, Antonarakis SE, Brunner HG, Buiting K, Cheung SW, Coffee B, Eggermann T, Francis D, Geraedts JP, Gimelli G, Jacobson SG, Le Caignec C, de Leeuw N, Liehr T, Mackay DJ, Montgomery SB, Pagnamenta AT, Papenhausen P, Robinson DO, Ruivenkamp C, Schwartz C, Steiner B, Stevenson DA, Surti U, Wassink T, Sharp AJ. DNA Methylation Profiling of Uniparental Disomy Subjects Provides a Map of Parental Epigenetic Bias in the Human Genome. Am J Hum Genet. 2016 Sep 1;99(3):555-566. https:/doi.org/ 10.1016/j.ajhg.2016.06.032. Epub 2016 Aug 25. PMID: 27569549; PMCID: PMC5011056.

11. Azzi S, Salem J, Thibaud N, et al. A prospective study validating a clinical scoring system and demonstrating phenotypical-genotypical correlations in Silver-Russell syndrome. J Med Genet. 2015;52(7):446-53. https:// doi.org/10.1136/jmedgenet-2014-102979.

12. Eggermann T, Mergenthaler S, Eggermann $\mathrm{K}$, et al. Identification of interstitial maternal uniparental disomy (UPD) (14) and complete maternal UPD(20) in a cohort of growth retarded patients. J Med Genet 2001;38(2):86-9. https://doi.org/10.1136/jmg.38.2.86.

13. Hjortshøj TD, Sørensen AR, Yusibova M, et al. upd(20)mat is a rare cause of the Silver-Russell-syndrome-like phenotype: Two unrelated cases and screening of large cohorts. Clin Genet. 2020;97(6):902-7. https://doi.org/ 10.1111/cge.13727.

14. Ashton EJ, Legrand $A$, Benoit $V$, et al. Simultaneous sequencing of 37 genes identified causative mutations in the majority of children with renal tubulopathies. Kidney Int. 2018;93(4):961-7. https://doi.org/10. 1016/j.kint.2017.10.016.

15. Hureaux M, Ashton E, Dahan K, et al. High-throughput sequencing contributes to the diagnosis of tubulopathies and familial hypercalcemia hypocalciuria in adults. Kidney Int. 2019;96(6):1408-16. https://doi.org/10. 1016/j.kint.2019.08.027

16. Richards S, Aziz N, Bale S, et al. Standards and guidelines for the interpretation of sequence variants: a joint consensus recommendation of the American College of Medical Genetics and Genomics and the Association for Molecular Pathology. Genet Med. 2015;17(5):405-24. https://doi. org/10.1038/gim.2015.30

17. Rehder CW, David KL, Hirsch B, et al. American College of Medical Genetics and Genomics: standards and guidelines for documenting suspected consanguinity as an incidental finding of genomic testing. Genet Med. 2013;15(2):150-2. https://doi.org/10.1038/gim.2012.169.

18. Spiteri BS, Stafrace Y, Calleja-Agius J. Silver-Russell syndrome: a review. Neonatal Netw. 2017;36(4):206-12. https://doi.org/10.1891/0730-0832. 36.4.206.

19. Hassold T, Hall H, Hunt P. The origin of human aneuploidy: where we have been, where we are going. Hum Mol Genet. 2007;16 Spec No. 2:R203-R208. https://doi.org/10.1093/hmg/ddm243

\section{Publisher's Note}

Springer Nature remains neutral with regard to jurisdictional claims in published maps and institutional affiliations.

Ready to submit your research? Choose BMC and benefit from

- fast, convenient online submission

- thorough peer review by experienced researchers in your field

- rapid publication on acceptance

- support for research data, including large and complex data types

- gold Open Access which fosters wider collaboration and increased citations

- maximum visibility for your research: over 100M website views per year

At $\mathrm{BMC}$, research is always in progress.

Learn more biomedcentral.com/submissions 